\title{
Emission Characteristics and Control Device Effectiveness of Particulate Matters and Particulate-phase PAHs from Urban Charbroiling Restaurants: A Field Test
}

\author{
Sang-Cheol Kim¹, Tae-Jung Lee', Jun-Min Jeon², Dong-Sool Kim¹, Young-Min Jo' ${ }^{\text {* }}$ \\ ${ }^{1}$ Department of Environmental Science and Engineering, Center for Fine Dust Research Kyung Hee University, Yonginsi \\ 17104, Korea \\ ${ }^{2}$ Green Environmental Complex Center, Suncheonsi 57992, Korea
}

\begin{abstract}
Urban restaurants that charbroil meat are a major emission source of fine particulate matter (PM) and polyaromatic hydrocarbons (PAHs) and receive frequent public complaints in large Korean cities. This study evaluated the effectiveness of newly installed pollution control equipment, including electrostatic precipitators (ESPs) and filters, at five charbroiling restaurants in different metropolitan areas near Seoul. The PM in the exhaust gas, which was sampled from the inflow and the outflow of the control devices, was measured with a 3-stage cascade impactor. The particle-bound PAHs, following pretreatment, extraction, and concentration, were then quantitatively analyzed using high-resolution gas chromatography-mass spectrometry (GC-MS). According to our field tests, the flue gas emitted by these five restaurants contained average $\mathrm{PM}_{10}$, $\mathrm{PM}_{2.5}$, and PAH concentrations of $22.6 \mathrm{mg} \mathrm{m}^{-3}, 22.1 \mathrm{mg} \mathrm{m}^{-3}$, and 4,127.1 $\mathrm{ng} \mathrm{m}^{-3}$, respectively. In addition, the ratio of the $\mathrm{PM}_{2.5}$ to the $\mathrm{PM}_{10}$ was 0.98 , and the correlation coefficient between the $\mathrm{PM}_{10}$ and the particulate-phase PAHs was 0.95 , suggesting a close relationship between the fine particle fraction and PAHs. The air pollution control equipment demonstrated an overall removal efficiency above $90 \%$, but specific cases exhibited an unexpectedly low efficiency (30\%), indicating the necessity of periodic cleaning and consistent maintenance.
\end{abstract}

Keywords: Charbroiling restaurants; $\mathrm{PM}_{10} ; \mathrm{PM}_{2.5}$; Particulate-phase PAHs; Control device.

\section{INTRODUCTION}

In recent years, there has been a proliferation of interest in the air quality of large cities. In addition to volatile organic compounds (VOCs), visible smoke containing fine particles and odors discharged from charbroiling restaurants mostly using grills deteriorates urban air, because the flue gas is exhausted without emissions control (Seo et al., 2015; Schauer et al., 1999). The amount of particulate matter (PM) exhausted from meat charbroiling is very small, comprised mostly of $\mathrm{PM}_{2.5}$ in tiny liquid or solid droplets (Lee, 1999; Lee et al., 2001; Lee et al., 2009). The fine particulate matters from charbroiling contain various noxious elements such as harmful gases, black carbon and polyaromatic hydrocarbons (PAHs) (Dockery and Stone, 2007; Brunekreef and Holgate, 2002).

According to the national statistics of 2015, biomass burning produced $12.5 \%\left(1,943.2 \mathrm{t} \mathrm{year}^{-1}\right)$ of the total $\mathrm{PM}_{2.5}$ $\left(16,145.6 \mathrm{t} \mathrm{year}^{-1}\right)$ in the metropolitan area; charbroiling

\footnotetext{
* Corresponding author.

Tel.: +82-31-2012485; Fax: +82-31-2034589

E-mail address: ymjo@khu.ac.kr
}

meat from domestic restaurants discharged $276.2 \mathrm{t}_{\text {year }}{ }^{-1}$ which corresponds to $1.7 \%$ (NIER, 2019). Seoul released $125.3 \mathrm{t}^{\text {year }}{ }^{-1}$ of $\mathrm{PM}_{2.5}$ to the atmosphere, $21.8 \%$ of the total national emissions; Gyeonggi-do followed with $124.8 \mathrm{t} \mathrm{year}^{-1}$. In addition to the associated health risks of heart attacks, lung damage, aggravated asthma, cancer and premature death due to disease, the discharging gas stream involves pungent smells generating a local nuisance and causing public complaints.

Nevertheless, since there are no legal standards or regulations to control charbroiling flue gas from restaurants in Korea, some local governments such as Gyeonggi-do have initiated investigation of field conditions and financing to support procurement of cleaning devices. Studies on fine particle charbroil exhaust have been carried out on a lab scale using chambers, and emission coefficients of PAHs and particulate matters have been evaluated depending on meat type and grilling method (Lee et al., 2009; Park et al., 2009; Bong et al., 2010; Kang et al., 2014; Park et al., 2015).

On the other hand, there have only been a limited number of studies that have attempted to evaluate the effectiveness of different control devices for local charbroiling restaurants (Lee et al., 2011). They have reported removal efficiencies of PM against the control facilities operated at charbroiling restaurants, which ranged from $54.62 \%$ to $98.98 \%\left(\mathrm{PM}_{2.5}\right)$, $54.76 \%$ to $98.98 \%\left(\mathrm{PM}_{10}\right)$, and $89.61 \%$ to $99.96 \%$ (the total 
PM [TMP]). In accordance, we attempted to investigate the emission characteristics of fine dust $\left(\mathrm{PM}_{10}\right.$ and $\left.\mathrm{PM}_{2.5}\right)$ and PAHs in particulate matters from five local restaurants serving traditional charbroiled items, and to evaluate the effectiveness of currently installed control devices based on in situ observation in this study.

\section{METHODS}

\section{Test Charbroiling Restaurants}

Test restaurants larger than $300 \mathrm{~m}^{2}$ were selected from the following five metropolitan cities in Korea: Yongin, Gunpo, Hanam, Osan and Bucheon. Table 1 summarizes the five test charbroiling restaurants. All of the sites served both charcoalbroiled beef and pork, but Restaurant $\mathrm{C}$ also served duck. Electrostatic precipitators (ESPs) prevented gas emissions at four of the restaurants from releasing the flue gas approximately 5,400 to $13,900 \mathrm{~m}^{3} \mathrm{~h}^{-1}$, and only Restaurant D discharged the waste gas of $4,500 \mathrm{~m}^{3} \mathrm{~h}^{-1}$ with a retrofitted filter type. Restaurants A and E had ESPs with a post-filter including packed beds with activated carbon granules. Restaurants B and C collect oil fumes, odors, and fine dust using an ESP with a cylindrical cell precipitator. Restaurant $\mathrm{D}$ used a porous ceramic filter (PCF) unit. In general, filtration using filters allowed lower flow rates than ESP (Restaurant B and C) due to the high pressure resistance. The smoke from the table was collected by individual hoods and conveyed through round duct line to the control unit. Each control unit was designed to aim for a $90 \%$ reduction in fine dust and 70\% reduction in odor (GGEC, 2019).

\section{Sampling and Analysis}

Exhaust gas was sampled from the inflow and outflow of the control devices as depicted in Fig. 1. As summarized in Table 2, we focused on busy hours in the evening (19:00-21:00), and took measurements twice in July and November of 2018.

A cascade impactor (Johnas II; Paul Gothe GmbH, Germany) with $47 \mathrm{~mm}$ polytetrafluoroethylene (PTFE) membrane filters with $0.5 \mu$ m open pores (Pall Corp., Mexico) designed according to the official method of International Standard Organization (ISO) 23210 was used to collect particulate matter (ISO, 2009). A 3-stage cascade impactor with a back-up stage was used to collect the particulates from the exhaust duct. The first stage of the impactor captured the particles larger than $10 \mu \mathrm{m}$, the second one collected the particles between $2.5 \mu \mathrm{m}$ and $10 \mu \mathrm{m}$, and the particles smaller than $2.5 \mu \mathrm{m}$ were retained in the third stage. In this study, based on the definition of the Korean standard testing method (ES 01301.1b) for PM measurement from flue gas stream, isokinetic sampling was achieved at 97-105\% according to the flow velocity and temperature of the flow (KMOE, 2019).

New filters were reserved in a desiccator for 24 hours before sampling, and weighed three times using an analytical electric balance with an accuracy of $0.01 \mathrm{mg}$. Dust concentration of the flue gas was evaluated by measuring the collected particulate matter amount with the same procedure as that for new filter papers (Bong et al., 2010).

Table 1. Summary of test restaurants.

\begin{tabular}{|c|c|c|c|c|c|}
\hline Restaurant & Location & Main Meat Type & Area $\left(m^{2}\right)$ & No. of Tables & $\begin{array}{l}\text { Control System } \\
\left(\text { capacity } \mathrm{m}^{3} \mathrm{~h}^{-1}\right)\end{array}$ \\
\hline A & Yongin-si & Beef & 360 & $39(8)^{\mathrm{a}}$ & $\operatorname{ESP}(5,400)$ \\
\hline B & Gunpo-si & Pork & 400 & $43(12)$ & $\operatorname{ESP}(11,600)$ \\
\hline $\mathrm{C}$ & Hanam-si & Duck & 400 & 37 (19) & $\operatorname{ESP}(13,900)$ \\
\hline $\mathrm{D}$ & Osan-si & Pork & 300 & $30(1)$ & PCF $(10,000)$ \\
\hline $\mathrm{E}$ & Bucheon-si & Pork & 330 & $44(10)$ & $\operatorname{ESP}(4,500)$ \\
\hline
\end{tabular}

${ }^{a}$ Number in the parentheses denotes those tables connected to hood and duct system.

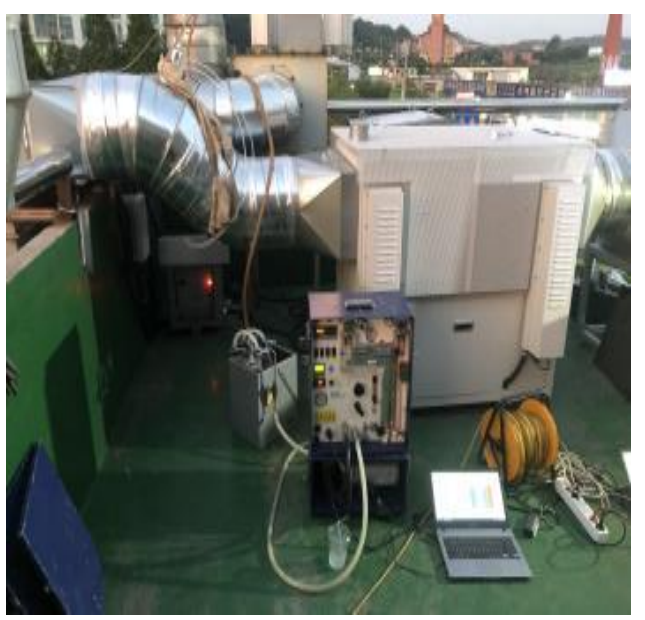

(a)

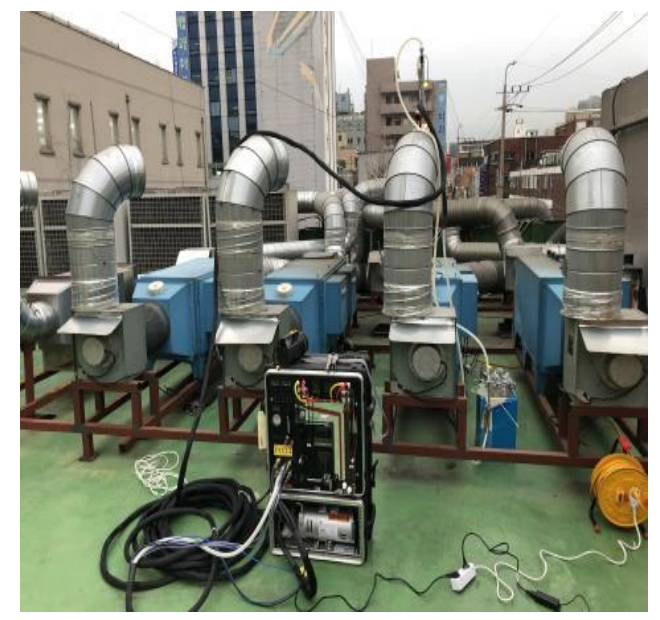

(b)

Fig. 1. View of on-site sampling: (a) Restaurant D and (b) Restaurant E. 
Table 2. Sampling conditions at each test restaurant.

\begin{tabular}{|c|c|c|c|c|c|c|c|}
\hline Item & & $\begin{array}{l}\text { Sampling } \\
\text { Date }^{\mathrm{a}}\end{array}$ & $\begin{array}{l}\text { Cleaning Date } \\
\text { of the Device }\end{array}$ & $\begin{array}{l}\text { Wt. of Broiled } \\
\text { Meat }(\mathrm{kg})\end{array}$ & $\begin{array}{l}\text { Exhaust } \\
\text { Velocity } \\
\left(\mathrm{m} \mathrm{s}^{-1}\right)\end{array}$ & $\begin{array}{l}\text { Flow Rate } \\
\left(\mathrm{m}^{3} \mathrm{~s}^{-1}\right)^{\mathrm{b}}\end{array}$ & $\begin{array}{l}\text { Sampling } \\
\text { Ratio } \\
(\%)\end{array}$ \\
\hline \multirow[t]{5}{*}{$1^{\text {st }}$} & $\mathrm{A}$ & $30 \mathrm{Jul}$ & $22 \mathrm{Jul}$ & Beef: 14; Pork: 4 & 4.4 & 2.2 & 102 \\
\hline & B & $31 \mathrm{Jul}$ & $27 \mathrm{Jul}$ & Pork: 13 & 3.5 & 2.0 & 99 \\
\hline & $\mathrm{C}$ & 3 Aug & $31 \mathrm{Jul}$ & Duck: 15 & 7.9 & 1.8 & 101 \\
\hline & $\mathrm{D}$ & 1 Aug & $29 \mathrm{Jul}$ & Pork: 3.3 & 2.8 & 2.4 & 102 \\
\hline & $\mathrm{E}$ & 2 Aug & $30 \mathrm{Jul}$ & Pork: 5 & 3.7 & 1.5 & 105 \\
\hline \multirow[t]{5}{*}{$2^{\text {nd }}$} & A & $20 \mathrm{Nov}$ & $10 \mathrm{Nov}$ & Beef: 12 ; Pork: 1 & 4.3 & 2.1 & 103 \\
\hline & $\mathrm{B}$ & $22 \mathrm{Nov}$ & 17 Nov & Pork: 10 & 5.9 & 2.0 & 97 \\
\hline & $\mathrm{C}$ & $24 \mathrm{Nov}$ & $14 \mathrm{Nov}$ & Duck: 12 & 7.5 & 1.7 & 101 \\
\hline & $\mathrm{D}$ & $23 \mathrm{Nov}$ & $7 \mathrm{Nov}$ & Pork: 3.3 & 2.6 & 1.8 & 103 \\
\hline & $\mathrm{E}$ & $21 \mathrm{Nov}$ & 3 Oct & Pork: 16 & 4.8 & 2.1 & 102 \\
\hline
\end{tabular}

${ }^{\mathrm{a}}$ In 2017.

${ }^{\mathrm{b}}$ Flow rate of air passing through the duct. $1^{\text {st }}$ sampling time $=20 \mathrm{~min}, 2^{\text {nd }}$ sampling time $=30 \mathrm{~min}$.

PM sampling for PAHs analysis followed an official regulation, CARB Method 429 (CARB, 1997) and ES01501.1a (NIER, 2018). CARB Method 429 describes a sampling method for both particulate-and gaseous-phase PAHs from stationary emission sources. This method recommends isokinetic extraction and collection of PAHs on an appropriate resin in impingers from the stack or in the upstream of flue gas (CARB, 1997).

Test PAHs comprised 23 species based on the Standard Method for Air Pollution Analysis (NIER, 2018). A highresolution gas chromatography-mass spectrometry (GC-MS) system (6890 GC/5973N MSD; Hewlett Packard, USA) was used for PAH quantification via the pre-treatment, extraction and concentration steps. The prepared sample gas $(1-2 \mu \mathrm{L})$ was injected into the GC-MS system. PAHs were extracted by solvent (hexane:acetone $=9: 1$ ) at $150^{\circ} \mathrm{C}$ for 15 minutes in an extractor (ASE 200E; Dionex Corp., USA), and then concentrated by an auto-centrifugal evaporator (TurboVap $\mathrm{LV}$; Zymark, USA). A curve calibration from $0.25 \mathrm{mg} \mathrm{L}^{-1}$ to $1 \mathrm{mg} \mathrm{L}^{-1}$ was used to quantify concentration for 16 compounds from $0.1 \mathrm{mg} \mathrm{mL}^{-1}$ to $2 \mathrm{mg} \mathrm{mL}^{-1}$ (Supelco, St. Louis, MO).

Table 3 describes the instrumental conditions used in the analysis. For quality control, filter and reagent blanks were analyzed and subtracted from the measured values of the samples. The limit of detection (LOD; ng) of PAHs was defined as the mean blank value plus three standard deviations. Prior to the sample analysis, the recovery rate was tested by spiking standards of 16 target PAHs on cleaned filters. The average recoveries of PAHs were $70-120 \%$.

\section{RESULTS AND DISCUSSION}

In this study, we investigated the effectiveness of air pollution control facilities in charbroiling restaurants to remove particulate matters. Particulate matter such as $\mathrm{PM}_{10}$ and $\mathrm{PM}_{2.5}$ contained in the exhaust gas flow, which are listed in the Korea Enforcement Decree of Clean Air Conservation ACT and as a U.S. Environmental Protection Agency (EPA) hazardous air pollutant (HAP), were closely investigated based on facility performance.

\section{Emission Characteristics \\ Particulate Matter}

The inflow amount of the particulate matters from charbroiling exhausts is summarized in Table 4. The highest average level of $\mathrm{PM}_{2.5}$ was $41.1 \mathrm{mg} \mathrm{m}^{-3}$ in Restaurant $\mathrm{C}$, and $38.5 \mathrm{mg} \mathrm{m}^{-3}, 14.1 \mathrm{mg} \mathrm{m}^{-3}, 12.6 \mathrm{mg} \mathrm{m}^{-3}$ and $4.3 \mathrm{mg} \mathrm{m}^{-3}$ for Restaurants A, E, D and B respectively. The collected particulate matters were distributed widely in size with working time, and the deviation by restaurant was large. A large amount of total particulate matters $\left(13.6 \mathrm{mg} \mathrm{m}^{-3}\right)$ was released from Restaurant $D$ that roasted $3.3 \mathrm{~kg}$ of pork, while Restaurant B cooking $10 \mathrm{~kg}$ and $13 \mathrm{~kg}$ of pork exhausted a relatively small amount of TPM $\left(4.6 \mathrm{mg} \mathrm{m}^{-3}\right)$. Restaurant C produced a very large amount of TPM when grilling greasy duck meat. Incomplete combustion from the conversion of

Table 3. Operation details of GC-MS for PAHs analysis.

\begin{tabular}{ll}
\hline Item & Conditions \\
\hline GC & $6890 \mathrm{GC}$ (Agilent Technologies) \\
Detector & 5973N MSD (Agilent Technologies) \\
Column & $\mathrm{J} \& \mathrm{~W} \mathrm{HP}-5(30 \mathrm{~m} \times 0.32 \mathrm{~mm} \times 0.25 \mu \mathrm{m}$; Agilent Technologies $)$ \\
Column flow & $1.5 \mathrm{~mL} \mathrm{~min}-1$ \\
Auto injector & $\mathrm{G} 4513 \mathrm{~A}$ \\
Purge flow & $\mathrm{He}(99.999 \%), 20.0 \mathrm{~mL} \mathrm{m^{-1 }}$ \\
Inlet temperature & $300^{\circ} \mathrm{C}$ \\
GC temperature program & $60^{\circ} \mathrm{C}(5 \mathrm{~min}) \rightarrow 10^{\circ} \mathrm{C} \mathrm{min} \rightarrow 200^{\circ} \mathrm{C}(5 \mathrm{~min}) \rightarrow 10^{\circ} \mathrm{C} \mathrm{min}^{-1} \rightarrow 200^{\circ} \mathrm{C}\left(5 \mathrm{~min}^{-1} \rightarrow\right.$ \\
& $310^{\circ} \mathrm{C}(10 \mathrm{~min}) \rightarrow 320^{\circ} \mathrm{C}(5 \mathrm{~min})$ \\
\hline
\end{tabular}


Table 4. Inflow concentrations of $\mathrm{PM}_{2.5}, \mathrm{PM}_{10}$ and TPM to control facilities at each site.

\begin{tabular}{llllll}
\hline Site & $\mathrm{PM}_{2.5}\left(\mathrm{mg} \mathrm{m}^{-3}\right)(\mathrm{range})$ & $\mathrm{PM}_{10}\left(\mathrm{mg} \mathrm{m}^{-3}\right)(\mathrm{range})$ & $\mathrm{TPM}\left(\mathrm{mg} \mathrm{m}^{-3}\right)(\mathrm{range})$ & $\mathrm{PM}_{2.5} / \mathrm{PM}_{10}$ & $\mathrm{PM}_{2.5} / \mathrm{TPM}$ \\
\hline A & $38.5(1.9-59.6)$ & $39.3(2.8-60.4)$ & $39.5(3.2-60.8)$ & 0.98 & 0.97 \\
B & $4.3(1.4-8.4)$ & $4.5(1.7-8.6)$ & $4.6(1.9-8.7)$ & 0.96 & 0.93 \\
C & $41.1(13.9-58.5)$ & $41.4(14.0-59.2)$ & $41.8(14.1-59.6)$ & 0.99 & 0.98 \\
D & $12.5(0.2-33.7)$ & $13.2(0.5-35.1)$ & $13.6(0.6-35.3)$ & 0.95 & 0.93 \\
E & $14.1(4.9-25.9)$ & $14.5(5.0-26.3)$ & $14.6(5.0-26.3)$ & 0.97 & 0.97 \\
Average & $22.1(0.2-59.6)$ & $22.6(0.5-37.9)$ & $22.8(0.6-60.8)$ & 0.98 & 0.97 \\
\hline
\end{tabular}

fat-forming elements in the meat to oily phases at high temperatures over charcoal generated a large amount of smoke. The concentration of particulate matter was highly related to meat type, grilling amount, fat content and seasonings added (Park et al., 2015; Heo et al., 2016).

On the other hand, the average emission factors (EFs) of PMs and PAHs for on-site cooking at five restaurants were evaluated and are summarized in Table 5. The values that were found in other references that were carried out with similar conditions are also listed. Restaurant $\mathrm{E}$ broiling both seasoned pork and raw pork belly showed lower EF values of PMs than other restaurants that mainly served marinated and seasoned meat. Korean charbroiling restaurants deal with meat marinated with various seasonings, so the smoke produced varies from site to site. Therefore, in this field test, particulate matters produced including oily impurities tended to adhere to the inner surface of the duct and final discharges to the control facility may have varied depending on the capacity of the hood and duct lines. As can be seen in Restaurant E, higher EF values appeared in simulated lab tests due to its simple duct line and excellent suction hood (Lee et al., 2020). Indeed, large quantities of waste gas could be dispersed inside the restaurant without being transported to the control facility. That was one of the reasons that lower EF values were collected from the entrance of the control facility.

Average mass concentrations of PM at the three size fractions are shown in Fig. 2. The highest concentrations of particles were observed at sizes $\leq 2.5 \mu \mathrm{m}$. The overall average emission rate of $\mathrm{PM}_{2.5}$ relative to $\mathrm{PM}_{10}$ for the 5 test restaurants was 0.98 , which indicated that most of the particulate matter formed from charbroiling fine dust was smaller than $2.5 \mu \mathrm{m}$. This value was slightly higher than other reported values such as 0.95 for pork roasting, 0.88 0.97 for various meats and 0.77 to 0.98 for pork and beef (Park et al., 2015; Heo et al., 2016). Most of the total particulate matter (TMP), 93-98\%, belonged to $\mathrm{PM}_{2.5}$. Thus, cooking meat by charbroiling generated a large amount of ultra-fine dust.

\section{PAHs}

The smoke generated by burning of fat contained a large proportion of PAHs (KFDA, 2007). Charbroiling meat released PAHs by decomposition of various organic elements at high temperatures between $550^{\circ} \mathrm{C}$ and $950^{\circ} \mathrm{C}(\mathrm{McD}$ onald et al., 2003). Since the PAH production rate decreased at temperatures greater than $800^{\circ} \mathrm{C}$, the fuel source and firing temperature were key factors for formation of PAHs. 23 species of PAHs in $\mathrm{PM}_{10}$ and $\mathrm{PM}_{2.5}$ in exhaust smoke were quantitatively identified and are summarized in Fig. 3.

The highest concentration of total PAHs contained in $\mathrm{PM}_{10}$, 6,761.4 $\mathrm{ng} \mathrm{m}^{-3}$, was found at Restaurant C, and Restaurant B discharged the least, $1,120.5 \mathrm{ng} \mathrm{m}^{-3}$. The maximum $\mathrm{PM}_{2.5}$ amount, 6,323.4 $\mathrm{ng} \mathrm{m}^{-3}$, was measured at Restaurant A, and

Table 5. Comparison of emission factor (EF) for PM $\left(\mathrm{g} \mathrm{kg}^{-1}\right)$ and PAHs $\left(\mathrm{mg} \mathrm{kg}^{-1}\right)$.

\begin{tabular}{|c|c|c|c|c|c|c|c|c|c|}
\hline \multirow{3}{*}{ Site } & \multirow{3}{*}{$\begin{array}{l}\text { Meat } \\
\text { Type }\end{array}$} & \multirow{3}{*}{$\mathrm{PM}$} & \multicolumn{7}{|c|}{ Emission Factor (g-PM kg-meat ${ }^{-1}$ ) } \\
\hline & & & \multicolumn{2}{|c|}{ This study } & \multirow{2}{*}{\multicolumn{3}{|c|}{ References }} & \multicolumn{2}{|c|}{ McDonald et al. (2003) } \\
\hline & & & PM & $\mathrm{PAHs}^{\mathrm{a}}$ & & & & PM & PAHs \\
\hline \multirow[t]{3}{*}{ A } & Beef & $\mathrm{PM}_{2.5}$ & 7.94 & 1.30 & $3.23^{\mathrm{b}}$ & - & $6.12^{\mathrm{e}}$ & 7.28 & 39.12 \\
\hline & & $\mathrm{PM}_{10}$ & 8.10 & 1.34 & $4.08^{b}$ & - & $6.31^{\mathrm{e}}$ & - & - \\
\hline & & TMP & 8.16 & - & $4.80^{\mathrm{b}}$ & - & - & - & - \\
\hline \multirow[t]{3}{*}{ B } & Pork & $\mathrm{PM}_{2.5}$ & 1.13 & 0.28 & $3.07^{\mathrm{b}}$ & $0.13^{\mathrm{c}}$ & $3.25^{\mathrm{e}}$ & & \\
\hline & & $\mathrm{PM}_{10}$ & 1.18 & 0.29 & $3.82^{\mathrm{b}}$ & $0.14^{\mathrm{c}}$ & $3.32^{\mathrm{e}}$ & - & - \\
\hline & & TMP & 1.21 & - & $3.87^{b}$ & $0.14^{\mathrm{c}}$ & & - & - \\
\hline \multirow[t]{3}{*}{$\mathrm{C}$} & Duck & $\mathrm{PM}_{2.5}$ & 7.87 & 0.84 & $8.12^{b}$ & - & $3.59^{\mathrm{e}}$ & 6.91 & 28.35 \\
\hline & & $\mathrm{PM}_{10}$ & 7.93 & 1.29 & $8.22^{b}$ & - & $3.97^{\mathrm{e}}$ & - & - \\
\hline & & TMP & 7.99 & - & $8.99^{b}$ & - & & - & - \\
\hline \multirow[t]{3}{*}{$\mathrm{D}$} & Pork & $\mathrm{PM}_{2.5}$ & 11.80 & 2.16 & - & - & - & 16.09 & 45.60 \\
\hline & & $\mathrm{PM}_{10}$ & 12.36 & 3.28 & - & - & - & - & - \\
\hline & & TMP & 12.74 & - & - & - & - & - & - \\
\hline \multirow[t]{3}{*}{$\mathrm{E}$} & Pork & $\mathrm{PM}_{2.5}$ & 2.48 & 0.46 & - & $4.15^{\mathrm{d}}$ & - & - & - \\
\hline & & $\mathrm{PM}_{10}$ & 2.53 & 0.48 & - & $4.72^{\mathrm{d}}$ & - & - & - \\
\hline & & TMP & 2.57 & - & - & $5.02^{\mathrm{d}}$ & - & - & - \\
\hline
\end{tabular}




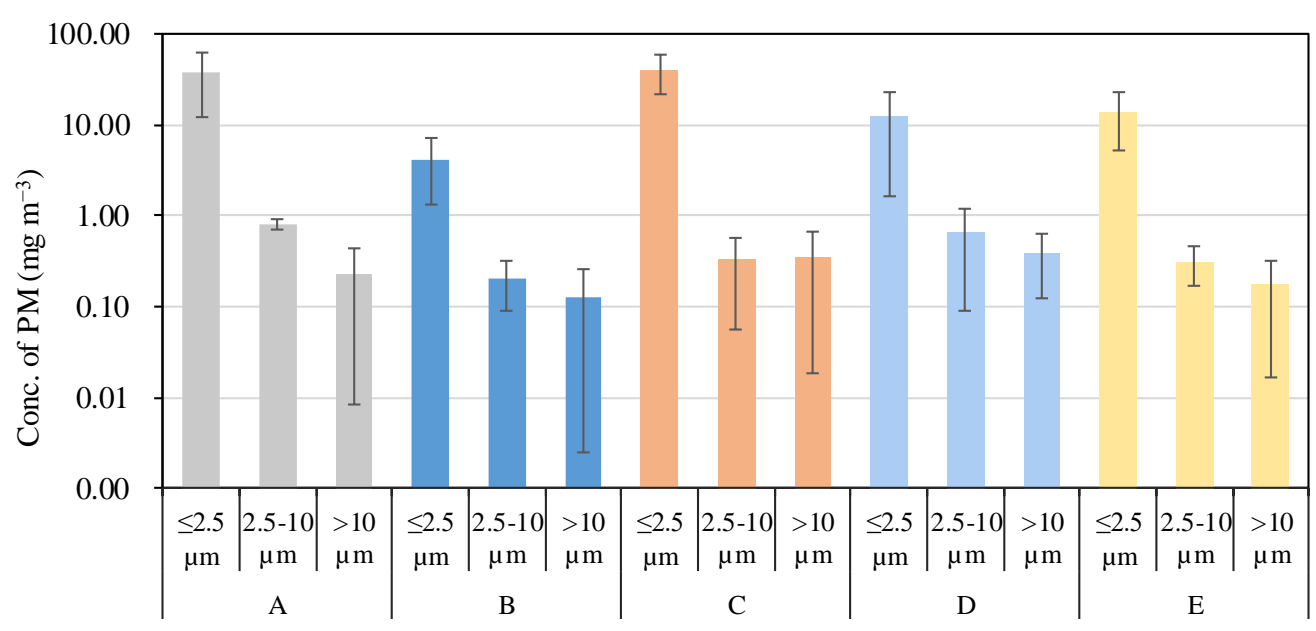

Fig. 2. Mass concentration distribution of different size groups of PM for each restaurant.
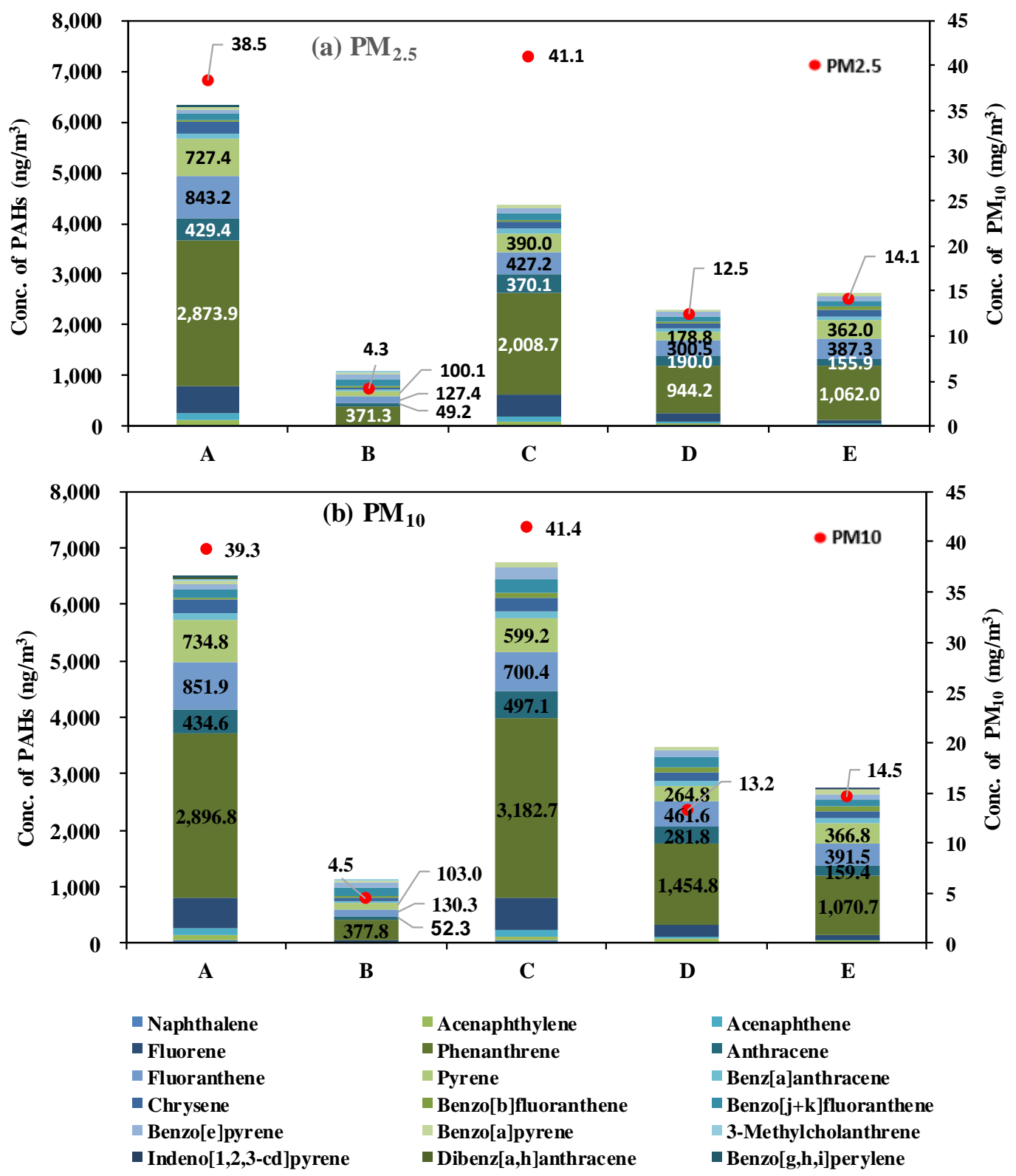

Fig. 3. Concentrations of total $\mathrm{PAHs}$ in (a) $\mathrm{PM}_{2.5}$ and (b) $\mathrm{PM}_{10}$ for each restaurant. 
the minimum amount, $1,065.4 \mathrm{ng} \mathrm{m}^{-3}$, was released from Restaurant B. Thus, the total PAHs concentrations varied widely depending on restaurants with the variables of meats, cooking amount, cooking pattern, griddle materials and ventilation power and system. In particular, emission rates tended to show proportionality to amount of particulate matter in the exhaust except at Restaurant C. Most PAHs for Restaurant $\mathrm{C}$, mainly grilling duck, were found at $\mathrm{PM}_{10}$. Although $99 \%$ of $\mathrm{PM}_{10}$ belongs to $\mathrm{PM}_{2.5}$, the total PAHs within $\mathrm{PM}_{2.5}$ was unexpectedly low, 2,388.7 $\mathrm{ng} \mathrm{m}^{-3}$, representing only $34.6 \%$ of $\mathrm{PM}_{10}$.

PAH compounds are classified with toxic equivalency factors (TEFs) based on a representative material's toxicity. For the U.S. EPA, the toxicity of benzo[a]pyrene is 1 , and other PAHs are labeled relatively as a conversion value of the toxic equivalency (TEQ). As a result of TEQ evaluation, Restaurant $\mathrm{C}$ showed the highest value, $165.1 \mathrm{ng}^{\mathrm{T}} \mathrm{TQ} \mathrm{m}^{-3}$, in $\mathrm{PM}_{10}$, which was similar to the concentration of total PAHs. The total PAH concentrations in $\mathrm{PM}_{2.5}$ were $6,323.4 \mathrm{ng} \mathrm{m}^{-3}$ and 2,636.1 $\mathrm{ng} \mathrm{m}^{-3}$ at Restaurants $\mathrm{A}$ and $\mathrm{D}$, respectively. However, by introducing TEF, Restaurant D, which contained more benzo[ $a]$ pyrene, showed a higher value of 99.9 ng-TEQ $\mathrm{m}^{-3}$ compared to Restaurant A with a value of 95.5 ng-TEQ $\mathrm{m}^{-3}$.

PAH emission factors $\left(\mathrm{mg} \mathrm{kg}^{-1}\right)$ within $\mathrm{PM}_{2.5}$ and $\mathrm{PM}_{10}$ of Restaurants A, B, C, D, and E were 1.30/1.34, 0.28/0.29, $0.84 / 1.29,2.16 / 3.28$, and 0.46/0.48, respectively (Table 5). All of the PAH emission factors in this study were lower than those of previous studies. McDonald et al. (2003) reported $\mathrm{PAH}$ emission factors within gas and $\mathrm{PM}_{2.5}$ from meat cooking under fired charbroiling (beef: 39.12 ; pork: 45.60; duck: 28.35).

Emission characteristics of PAH compounds according to the number of aromatic rings were investigated in terms of the summation of concentrations with ring type and fraction of total PAHs, as summarized in Fig. 4. The PAH emission rates in this study were dominated by 3-4-ring compounds, with a value of $3,998.3 \mathrm{ng} \mathrm{m}^{-3}$ for 3-ring PAHs including acenaphthene, fluorene, phenanthrene and anthracene from Restaurant A, representing $61.4 \%$ of total PAHs. Other test restaurants also produced high 3-ring $\mathrm{PAH}$ amounts: $452.3 \mathrm{ng} \mathrm{m}^{-3}$ (40.4\%), 4,355.7 $\mathrm{ng} \mathrm{m}^{-3}$ (64.4\%), 1,981.2 $\mathrm{ng} \mathrm{m}^{-3}$ $(56.8 \%)$ and $1,315.2 \mathrm{ng} \mathrm{m}^{-3}(46.8 \%)$ for Restaurant B, C, D, and $\mathrm{E}$ respectively.

Only a small amount of compounds containing 6 rings such as indeno[1,2,3-cd]pyrene, dibenz $[a, h]$ anthracene, and benzo[ghi]perylene were found from the test restaurants except for Restaurant $\mathrm{A}$. The average value by ring number for five restaurants was $58.6 \%$ for those with 3 rings, $28.4 \%$ with 4 rings, $10.6 \%$ with 5 rings, $2.0 \%$ with 2 rings and $0.4 \%$ with 6 rings.

The results of the present investigation show that, while release of compounds with a moderate boiling point (approximately $300-400^{\circ} \mathrm{C}$ ) was low, such PAHs containing 3-4 rings tended to exist at high levels in the emission flow. High-boiling-point compounds with 5-6 rings at temperatures above $500^{\circ} \mathrm{C}$ were maintained at low levels in the emissions. Similar tendencies were found in other domestic studies; for example, 2-3-ring PAHs or 3-4-ring PAHs occupied the largest amounts of compounds (Choi, 2013; Lee, 2011). In contrast, one study found high proportions of 4-6-ringed PAHs in emission gases of meat roasting (Li et al., 2018). This result was attributed to fat contents and added seasonings in addition to the cooking conditions based on cultural food background.

Fig. 5 depicts the average mass distribution of individual polyaromatic hydrocarbons for charbroiling emissions from all of the test restaurants. Among the 23 species, phenanthrene, fluoranthene, pyrene, anthracene, and fluorine appeared in the largest amounts, in that order. Phenanthrene accounted for $44.5 \%, 33.7 \%, 47.1 \%, 41.7 \%$ and $38.9 \%$ of the total PAHs for each test restaurant. Whilst, very little dibenzopyrene isomer composed of 6 rings, which is a potential carcinogenic aromatic hydrocarbon was detected.

Benzo $[a]$ pyrene was released at values of $60.5 \mathrm{ng} \mathrm{m}^{-3}$, $43.3 \mathrm{ng} \mathrm{m}^{-3}, 106.0 \mathrm{ng} \mathrm{m}^{-3}, 70.2 \mathrm{ng} \mathrm{m}^{-3}$, and $81.4 \mathrm{ng} \mathrm{m}^{-3}$ from Restaurants A, B, C, D, and E, respectively. The respective emission rates were $0.9 \%, 3.9 \%, 1.6 \%, 2.0 \%$, and $3.0 \%$, with an average of $1.8 \%$. The correlation coefficient between PAHs and benzo[a]pyrene was high at 0.78 . The Korean

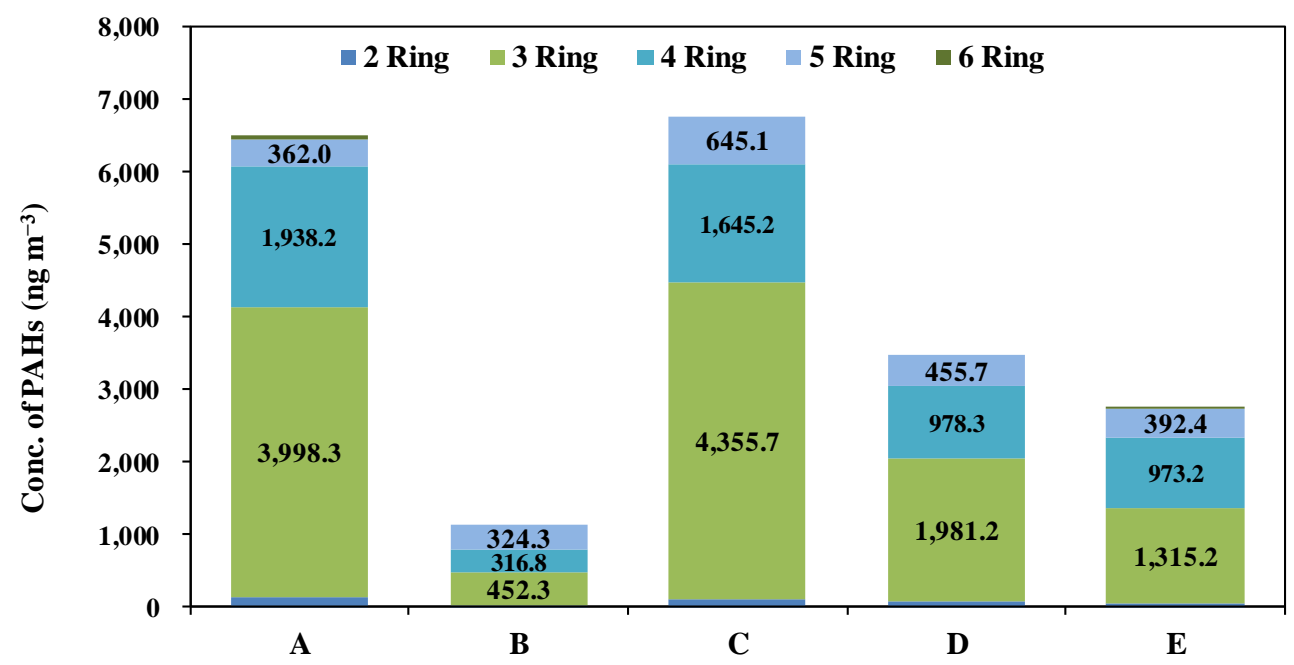

Fig. 4. Average concentration of $\mathrm{PAHs}$ in $\mathrm{PM}_{10}$ released from charbroiling sources according to number of benzene rings. 


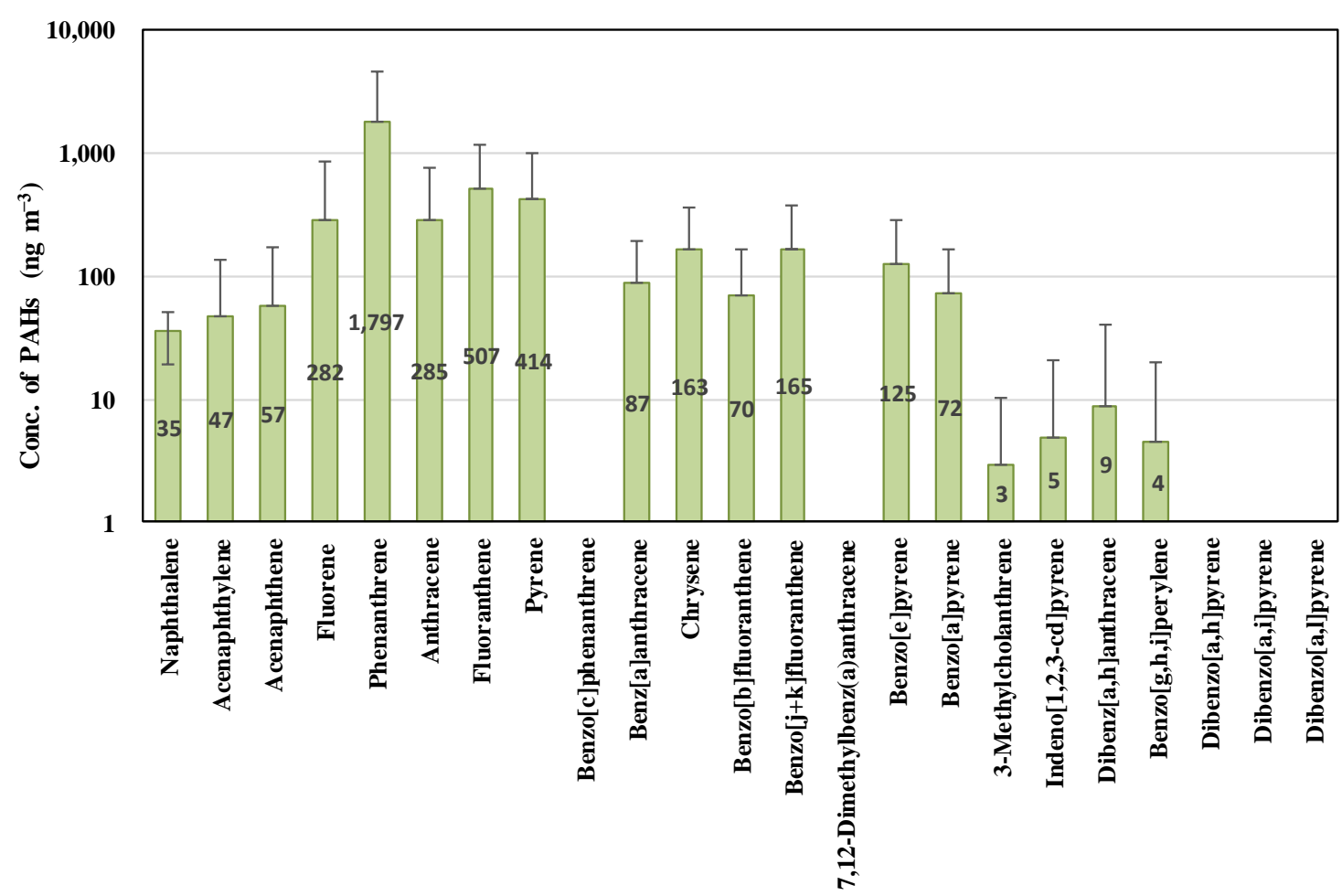

Fig. 5. Average individual PAH concentrations emitted from the test charbroiling restaurants.

Ministry of Environment established legislation for emission standards of 8 PAHs including benzo[a]pyrene that will go into effect in 2020 (ME, 2018). The national standard allows a discharge of $0.05 \mathrm{mg} \mathrm{m}^{-3}$ from an emission source. The measured values in this study were much lower than the government guideline. However, charbroiling restaurants are common in residential and commercial areas, and emit harmful pollutants that can be dispersed into the surrounding areas.

An investigation into the effects of the degree of roasting on PMs and PAH emissions was attempted at Restaurant D as summarized in Table 6 . While pork $(3.3 \mathrm{~kg})$ was roasted on "medium" for the first investigation, the second test was served "very well done," with a slightly burned surface. An examination focusing on PMs and PAHs emissions showed an obvious difference according to roasting conditions. The concentration of $\mathrm{PM}_{10}$ increased by almost 52 times from $0.5 \mathrm{mg} \mathrm{m}^{-3}$ for general "medium broiling" to $25.8 \mathrm{mg} \mathrm{m}^{-3}$ for slight surface burning. Total PAHs in $\mathrm{PM}_{10}$ also increased from $62.4 \mathrm{ng} \mathrm{m}^{-3}$ to $6,918.1 \mathrm{ng} \mathrm{m}^{-3}$, an increase of approximately 111 times. Benzo[a]pyrene, known primary carcinogen, greatly increased from $6.5 \mathrm{ng} \mathrm{m}^{-3}$ to $134.0 \mathrm{ng} \mathrm{m}^{-3}$.

It can be concluded that the cooking method, particularly charbroiling, directly influences the emission amounts of PAHs and particulate matter. In the traditional culture of Korea, people prefer "well-done" to "raw" meat. Therefore, environmental and health aspects should be taken into consideration at charbroiling restaurants. Grilling assistants and nearby residents could be consistently exposed to hazardous species. This long-term exposure, even at low levels, may be more harmful than direct inhalation by customers (Badyda et al., 2018).

\section{Dependency of PAH Emission on Particulate Matters}

The mass proportions of PAHs discharged from meat charbroiling were $0.01633-0.02644$ wt $\%$ for $\mathrm{PM}_{10}$ and 0.0034-0.0326 wt\% for $\mathrm{PM}_{2.5}$. For reference, Seo et al. (2010) found values of $0.02585 \mathrm{wt} \%$ and $0.06630 \mathrm{wt} \%$ for pork and beef grilling, respectively. Fig. 6 compares the correlations of PAHs to concentrations of $\mathrm{PM}_{10}$ and $\mathrm{PM}_{2.5}$, and the overall coefficients were 0.9522 and 0.8944 , respectively. The second uncertain release from Restaurant $\mathrm{C}$ introduced a slightly lower correlation coefficient $\left(\mathrm{R}^{2}\right)$ for $\mathrm{PM}_{2.5}$. Such irregular performances may be common in practice. Thus, after-treatment facilities must be designed to handle a sufficient capacity.

Since particle-bound PAHs were investigated in this study, the relationship was quite linear with high dependencies for both $\mathrm{PM}_{10}$ and $\mathrm{PM}_{2.5}$. Nevertheless, the linearity varied by restaurant. As a consequence, and as more particulates were discharged, more harmful PAHs were emitted.

\section{Evaluation of Abatement Efficiency}

The effectiveness of control devices for $\mathrm{PM}_{2.5}, \mathrm{PM}_{10}$ and TPM is summarized in Table 7. Abatement efficiency was evaluated by averaging repeated measurements of particulate matter before and after the devices operated in test restaurants. The first investigation during July of 2018 capture efficiency values for $\mathrm{PM}_{2.5}: 99.1 \%$ for Restaurant $\mathrm{A}, 31.5 \%$ for $\mathrm{B}$, $92.5 \%$ for C, $39.6 \%$ for D, and $92.9 \%$ for E. However, the absolute amount of final exhaust was $0.6 \mathrm{mg} \mathrm{m}^{-3}$ from Restaurant A, $1.7 \mathrm{mg} \mathrm{m}^{-3}$ from $\mathrm{B}, 4.1 \mathrm{mg} \mathrm{m}^{-3}$ from $\mathrm{C}$, $0.1 \mathrm{mg} \mathrm{m}^{-3}$ from $\mathrm{D}$ and $0.9 \mathrm{mg} \mathrm{m}^{-3}$ from $\mathrm{E}$. The second measurement in November of 2018 showed respective capture efficiency of $98 \%, 90.2 \%, 88.3 \%, 94.9 \%$ and $23.8 \%$ 
Table 6. Emissions of $\mathrm{PM}_{10}$ and PAHs depending on roasting conditions at Restaurant D.

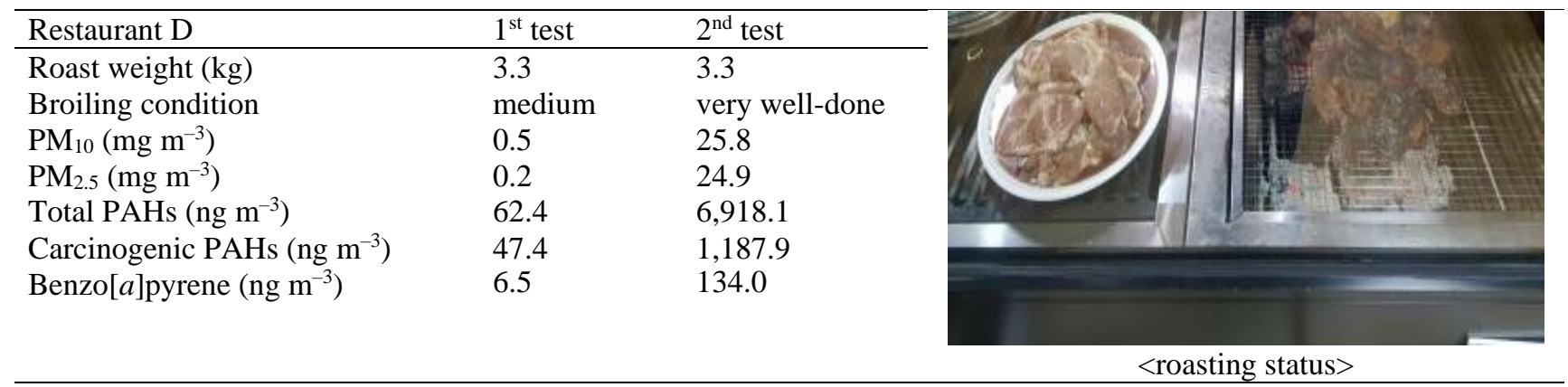
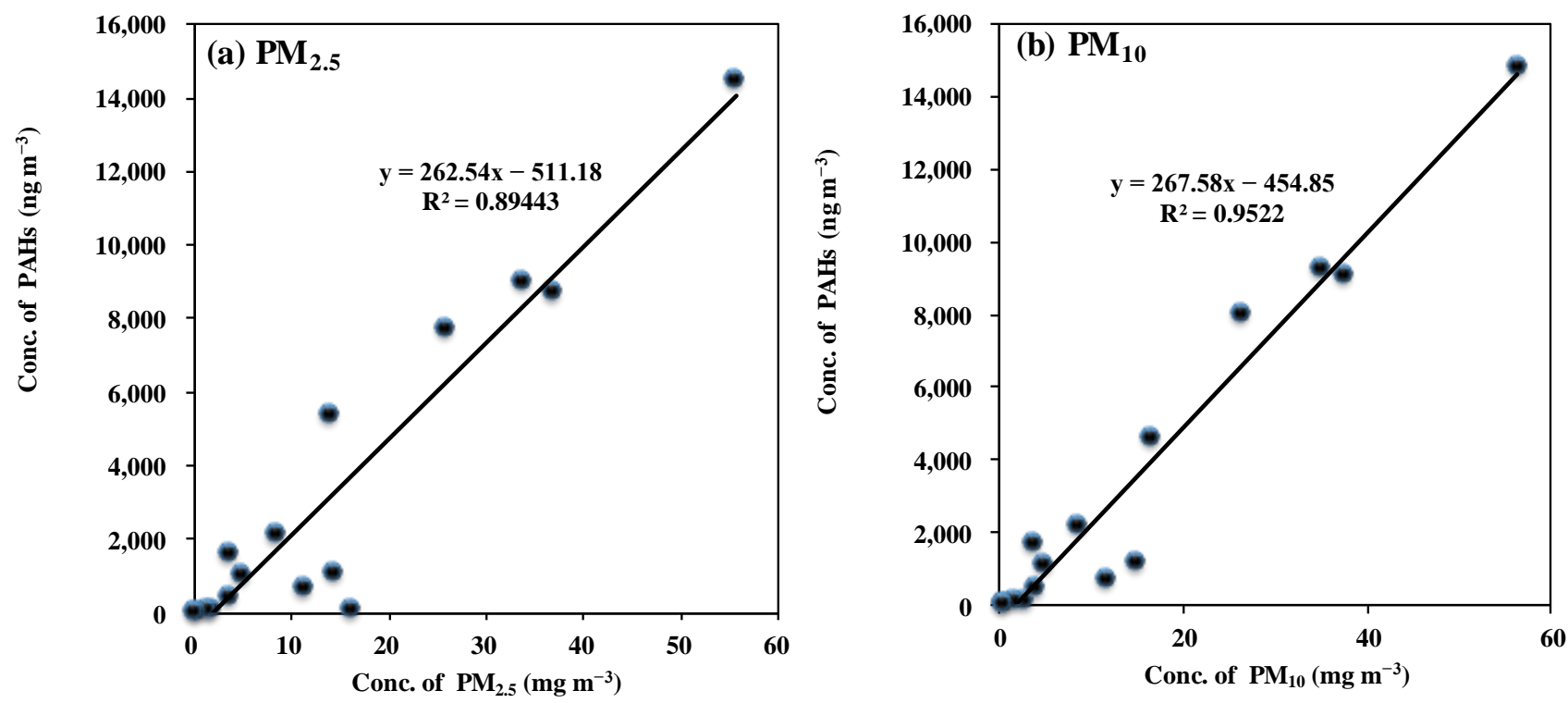

Fig. 6. Correlations of PMs and PAHs concentration for all of the test restaurants.

for the restaurants. The mass concentration of $\mathrm{PM}_{2.5}$ after use of the control devices was very low, ranging from $0.3 \mathrm{mg} \mathrm{m}^{-3}$ to $4.1 \mathrm{mg} \mathrm{m}^{-3}$. Restaurants B and D had low PM concentrations for the first measurement before the device showed very low dust capture efficiency. Although it is difficult to handle low-concentration flows, the current facilities mitigate the output of fine particulates and probably PAHs up to certain levels.

Restaurant D using a filtration device showed $94.4 \%$ and 94.5\% reduction for $\mathrm{PM}_{2.5}$ and $\mathrm{PM}_{10}$ in the second test compared to the removal efficiency in the first test, likely due to the very low inlet flow rate and concentration. Since filter efficiency is closely related to flow inertia, low dust loading and low flow velocity might have resulted in low efficiency. On the contrary, filter-type dust collectors would be clogged by fine particulate matter without being cleaned for a long time. Thus, tightened filter media can capture the dust with high efficiency.

The device performance for $\mathrm{PM}_{2.5}$ at Restaurant $\mathrm{E}$ dropped from $92.9 \%$ in the first investigation to $24 \%$ in the second. Despite similar inlet concentrations to the device, $12.9 \mathrm{mg} \mathrm{m}^{-3}$ and $15.4 \mathrm{mg} \mathrm{m}^{-3}$, the downstream concentrations were $0.9 \mathrm{mg} \mathrm{m}^{-3}$ and $11.7 \mathrm{mg} \mathrm{m}^{-3}$ respectively. One of the key factors used to determine control efficiency was maintenance of the facility. While the first measurement was carried out 2 days after cleaning, the second was performed after 21 days of operation. In other words, the cleaning interval was closely associated with capture performance, particularly in an ESP.

However, the test beds, Restaurants B and D, showed exceptional inconsistencies between those operation parameters. If the amount of inlet PM was very small, a meaningful evaluation of treatment efficiency of the control facilities could not be obtained. First of all, it seems that discretionary operation and management of the site determined the effectiveness of the air purifier. Thus, air pollution control devices including ventilation ducts and hoods in charbroil restaurants must not be prepared only based on the theoretical design, but on-site applications should also be considered.

As for the PAHs shown in Fig. 7, Restaurant A with 6 small ESPs with individual capacities of $30 \mathrm{~m}^{3} \mathrm{~min}^{-1}$, removed both PMs and PAHs with high efficiency. Restaurants $\mathrm{B}, \mathrm{D}$ and $\mathrm{E}$ showed an apparent dependency of PAH removal efficiency on particulate collection. Despite the high-efficiency removal of PMs in Restaurant $\mathrm{D}$, the $\mathrm{PAH}$ removal efficiencies for the second measurement were only $47.4 \%$ and $26.2 \%$ for $\mathrm{PM}_{10}$ and $\mathrm{PM}_{2.5}$ respectively. The reason that 
Table 7. Reduction efficiency of particulate matters by control facilities.

\begin{tabular}{|c|c|c|c|c|c|c|c|}
\hline \multirow[b]{2}{*}{ Restaurant } & \multirow[b]{2}{*}{ PM } & \multicolumn{3}{|c|}{$1^{\text {st }}$ measurement } & \multicolumn{3}{|c|}{$2^{\text {nd }}$ measurement } \\
\hline & & $\begin{array}{l}\text { Control } \\
\text { Facility } \\
\text { Inlet Conc. } \\
\left(\mathrm{mg} \mathrm{m}^{-3}\right)\end{array}$ & $\begin{array}{l}\text { Control } \\
\text { Facility } \\
\text { Outlet Conc. } \\
\left(\mathrm{mg} \mathrm{m}^{-3}\right)\end{array}$ & $\begin{array}{l}\text { Control } \\
\text { Efficiency } \\
(\%)\end{array}$ & $\begin{array}{l}\text { Control } \\
\text { Facility } \\
\text { Inlet Conc. } \\
\left(\mathrm{mg} \mathrm{m}^{-3}\right)\end{array}$ & $\begin{array}{l}\text { Control } \\
\text { Facility } \\
\text { Outlet Conc. } \\
\left(\mathrm{mg} \mathrm{m}^{-3}\right)\end{array}$ & $\begin{array}{l}\text { Control } \\
\text { Efficiency } \\
\text { (\%) }\end{array}$ \\
\hline \multirow[t]{3}{*}{$\mathrm{A}$} & $\mathrm{PM}_{2.5}$ & 30.8 & 0.3 & 99.1 & 46.2 & 0.91 & 98.0 \\
\hline & $\mathrm{PM}_{10}$ & 31.6 & 0.6 & 98.2 & 47.0 & 0.95 & 98.0 \\
\hline & TMP & 32.0 & 0.9 & 97.3 & 47.1 & 0.98 & 97.9 \\
\hline \multirow[t]{3}{*}{ B } & $\mathrm{PM}_{2.5}$ & 2.5 & 1.7 & 31.5 & 6.1 & 0.59 & 90.2 \\
\hline & $\mathrm{PM}_{10}$ & 2.8 & 2.0 & 26.7 & 6.2 & 0.63 & 89.8 \\
\hline & TMP & 3.0 & 2.3 & 23.2 & 6.2 & 0.66 & 89.4 \\
\hline \multirow[t]{3}{*}{$\mathrm{C}$} & $\mathrm{PM}_{2.5}$ & 54.6 & 4.1 & 92.5 & 27.6 & 3.22 & 88.3 \\
\hline & $\mathrm{PM}_{10}$ & 55.1 & 4.4 & 91.9 & 27.7 & 3.30 & 88.1 \\
\hline & TMP & 55.7 & 4.8 & 91.3 & 27.8 & 3.35 & 87.9 \\
\hline \multirow[t]{3}{*}{$\mathrm{D}$} & $\mathrm{PM}_{2.5}$ & 0.2 & 0.1 & 39.6 & 24.9 & 1.40 & 94.4 \\
\hline & $\mathrm{PM}_{10}$ & 0.5 & 0.4 & 31.1 & 25.8 & 1.41 & 94.5 \\
\hline & TMP & 1.2 & 0.8 & 34.1 & 25.9 & 1.41 & 94.6 \\
\hline \multirow[t]{3}{*}{ E } & $\mathrm{PM}_{2.5}$ & 12.9 & 0.9 & 92.9 & 15.4 & 11.7 & 24.4 \\
\hline & $\mathrm{PM}_{10}$ & 13.3 & 1.3 & 90.3 & 15.6 & 11.9 & 23.8 \\
\hline & TMP & 13.6 & 1.6 & 88.3 & 15.7 & 12.0 & 23.8 \\
\hline
\end{tabular}

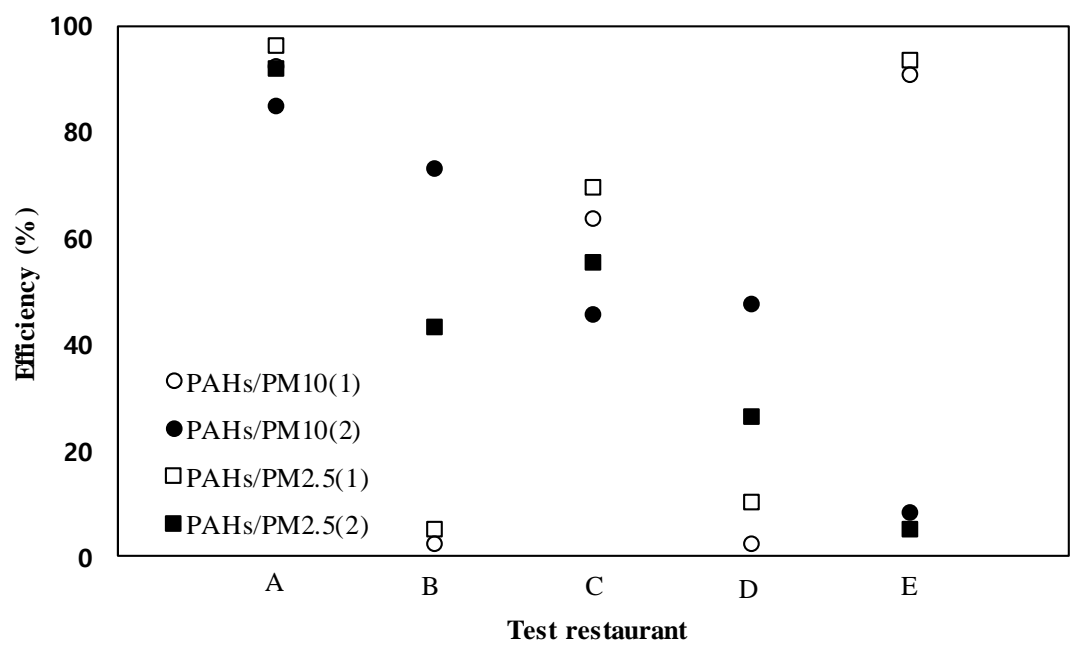

Fig. 7. Abatement efficiency of total PAHs in (a) $\mathrm{PM}_{2.5}$ and (b) $\mathrm{PM}_{10}$.

$\mathrm{PAH}$ removal was not as high as that of PM seemed to be the addition of compounds remaining in the filter to the fine particles in the exhaust. The current control facilities that focus on particulate matter mitigation are inadequate for gaseous pollutants such as PAHs, odors, and other potential materials including $\mathrm{NO}_{x}$ and $\mathrm{SO}_{x}$. Although they are much reduced, these hazardous pollutants should be reduced even more through additional collectors.

\section{CONCLUSIONS}

This study focused on the performance of air pollution control devices in filtering the PM and particulate-phase PAHs generated by urban charbroiling restaurants. Four of the five test restaurants (the exception being Restaurant B) emitted fine particles $\left(\mathrm{PM}_{10}\right)$ at levels that exceeded the national guideline $\left(10-70 \mathrm{mg} \mathrm{m}^{-3}\right)$; in particular, $\mathrm{PM}_{2.5}$ formed more than $90 \%$ of the total particulate matter. Furthermore, the concentrations of the $\mathrm{PM}_{2.5}$ and $\mathrm{PM}_{10}$ displayed strong correlations with that of the particulatephase PAHs $\left(\mathrm{R}^{2}=0.8944\right.$ and 0.9522 , respectively). Many of these PAHs were characterized by moderate to high boiling points, i.e., they were composed of 3 or more aromatic rings, with phenanthrene (b.p.: $336^{\circ} \mathrm{C}$ ) contributing $41.1 \%$ of the total PAH emissions. The primary carcinogen, benzo $[a]$ pyrene, exhibited an average concentration of $72.3 \mathrm{ng} \mathrm{m}^{-3}$, which is lower than the emission guideline for general industry $\left(0.05 \mathrm{mg} \mathrm{m}^{-3}\right)$. The installed pollution control equipment at the test restaurants achieved average reduction efficiencies of $88.7 \%$ for $\mathrm{PM}_{2.5}$ and $88.1 \%$ for $\mathrm{PM}_{10}$, and the emitted PAHs decreased with the particulates. However, the devices at the different restaurants varied in terms of success, and we observed inconsistent parametric relations in some of the cases. 


\section{ACKNOWLEDGEMENTS}

This research was conducted as part of the Establishment of Proper Management Guidelines of Air Pollution Control Device and Environmental Impact Survey of the Charbroiling Restaurants (18-05-01-40-41) supported by the Gyeonggi Green Environment Center in 2018 and the Technology Development Program to Solve Climate Changes supported by the National Research Foundation (NRF) funded by the Ministry of Science, ICT (2017M1A2A2086819).

\section{REFERENCES}

Badyda, A.J., Widziewicz, K., Rogula-Koztowska, W., Majewski, G. and Jureczko, I. (2018). Inhalation exposure to PM-bound polycyclic aromatic hydrocarbons released from barbecue grills powered by gas, lump charcoal and charcoal briquettes. In Pulmonary Disorders and therapy, advances in experimental medicine and biology, Pokorski, M. (Ed.), Springer International Publishing, Cham, pp. 11-27.https://doi.org/10.1007/5584_2017_51

Brunekreef, B. and Holgate, S.T. (2002). Air pollution and health. Lancet 360: 1233-1242. https://doi.org/10.1016/S 0140-6736(02)11274-8

Bong, C.K., Park, S.J., Park, S.G., Kim, J.H. and Hwang, U.H. (2010). The study on the emission characteristics of particulate matters from meat cooking. J. Korean Soc. Environ. Eng. 33: 196-291. https://doi.org/10.4491/KSE E.2011.33.3.196

California Air Resources Board (CARB) (1997). Method 429: Determination of polycyclic aromatic hydrocarbon (PAH) emissions from stationary sources. http://www.arb. ca.gov/testmeth/vol3/m_429.pdf

Choi, H.J. (2013). Characteristics of hazardous substances emitted from charcoal grilling of meat, $\mathrm{PhD}$ dissertation, Kangwon National University, Korea.

Dockery, D.W. and Stone, P.H. (2007). Cardiovascular risks from fine particulate air pollution. N. Engl. J. Med. 356: 511-513. https://doi.org/10.1056/NEJMe068274

Gyeonggi Green Environment Center (GGEC) (2019). Establishment of guidelines for proper management of air pollution prevention facilities and environmental impact investigation. Gyeonggi Green Environment Center, pp. 39-65.

Heo, S.H., Kim, J.H., Jo, M.R., Hong, J.H. and Kang, D.I. (2016). A study on the emission characteristics of hazardous air pollutants (HAPs) and particulate matters from under-fired briquette (Yeontan) broiling. J. Korean Soc. Urban Environ. 16: 169-178. https://www.earticle. net/Article/A285923

International Organization for Standardization (ISO) (2009). ISO 23210:2009 (2-stage cascade impactor): Stationary source emissions - Determination of $\mathrm{PM}_{10} / \mathrm{PM}_{2.5}$ mass concentration in flue gas - Measurement at low concentrations by use of impactors. International Organization for Standardization.

Korea Food and Drug Administration (KFDA) (2007). What are PAHs in food? Korea Food and Drug Administration, Korea.
Korea Ministry of Environment (KMOE) (2019). Air measurement standard method. http://www.law.go.kr

Kang, B.W., Jeon, J.M. and Lee, H.S. (2014). A study on the source profile development for fine particles emitted from meat cooking. J. Korean Soc. Atmos. Environ. 30: 18-25. https://doi.org/10.5572/KOSAE.2014.30.1.018

Lee, J.B. (2011). A Study on Characteristics of particulate matter generated from the under-fired charbroiling of meat, $\mathrm{PhD}$ dissertation, University of Seoul, Korea.

Lee, S.Y. (1999). Emissions from street vendor cooking devices (charcoal grilling). U.S. Environmental Protection Agency, Washington, DC, EPA/600/R-99/048.

Lee, J.B., Kim, H.J., Jung, K. and Kim, S.D. (2009). Emission characteristics of particulate matters from under-fired charbroiling cooking process using the hood method. Korean J. Environ. Health Sci. 35: 315-321. https://doi.org/10.5668/JEHS.2009.35.4.315

Lee, J.B., Lom, K.H., Kim, H.J., Cho, S.J., Kung, K. and Kim, S.D. (2011). Emission rate of particulate matter and its removal efficiency by precipitators in under-fired charbroiling restaurants. Sci. World J. 11: 1077-1088. https://doi.org/10.1100/tsw.2011.103

Lee, S.C., Li, W.M. and Chan, L.Y. (2001). Indoor air quality at restaurants with different styles of cooking in metropolitan Hong Kong. Sci. Total Environ. 279: 181193. https://doi.org/10.1016/S0048-9697(01)00765-3

Lee, Y.Y., Park, H., Seo, Y., Yun, J., Kwon, J., Park, K.W., Han, S.B., Oh, K.C., Jeon, J.M. and Cho, K.S. (2020). Emission characteristics of particulate matter, odors, and volatile organic compounds from the grilling of pork. Environ. Res. 183: 109162. https://doi.org/10.1016/j.env res.2020.109162

Li, Y.C., Qiu, J.Q., Shu, M., Ho, S.S., Cao, J.J., Wang, G.H., Wang, X.X. and Zhao, X.Q. (2018). Characteristics of polycyclic aromatic hydrocarbons in $\mathrm{PM}_{2.5}$ emitted from different cooking activities in China. Environ. Sci. Pollut. Res. 25: 4750-4760. https://doi.org/10.1007/s11356-0170603-0

McDonald, J., Zielinska, B., Fujita, E., Sagebiel, J., Chow, J. and Wastson, J. (2003). Emissions from charbroiling and grilling of chicken and beef. J. Air Waste Manage. Assoc. 53: 185-194. https://doi.org/10.1080/10473289.2 003.10466141

Ministry of Environment (ME) (2018) Ministry of Environment Announcement No. 2018-616, Korea.

National Institute of Environmental Research (NIER) (2019). National air pollutants emission service, http://airemiss.nier.go.kr/mbshome/mbs/airemiss/index.do

National Institute of Environmental Research (NIER) (2018). Air pollution measurement analysis test standard ES 01505.1a Polycyclic Aromatic Hydrocarbons (PAHs), http://www.law.go.kr/LSW/admRulInfoP.do?admRulSe $\mathrm{q}=2100000171831 \#$

Park, S.K., Choi, S.J., Park, G.J., Kim, J.Y., Bong, C.K., Park, S.J., Hwang, U.H. and Kim, J.H. (2009). Experimental study on the controller of oil mist and PM from meat cooking. J. Korean Soc. Urban Environ. 9: 9398. https://www.earticle.net/Article/A115544

Park, S.K., Choi, S.J., Kim, J.Y., Lee, H.J., Jang, Y.K., 
Bong, C.K., Kim, J.H., Hwang, U.H (2011). A study on the development of particulate matters emission factors from biomass burning: Mainly commercial meat cooking. J. Korean Soc. Atmos. Environ. 27: 426-435. https://doi.org/10.5572/KOSAE.2011.27.4.426

Park, S.K., Kim, D.K., Hwang, U.H., Lee, J.J., Lee, J.B., Bae, I.S., Eo, S.M. and Jung, K. (2015). Emission characteristics of air pollutants from meat charbroiling. $J$. Clim. Change Res. 6: 311-318. https://doi.org/10.15531/ ksccr.2015.6.4.311

Schauer, J.J., Kleema, M.J., Cass, G.R. and Simoneit, B.R.T. (1999). Measurement of emissions from air pollution sources. 1. $\mathrm{C}_{1}$ through $\mathrm{C}_{29}$ organic compounds from meat charbroiling. Environ. Sci. Technol. 33: 15661577. https://doi.org/10.1021/es980076j

Seo, Y.H., Ko, K.Y. and Jang, Y.K. (2010). Determination of cholesterol, fatty acids and poly aromatic hydrocarbon in $\mathrm{PM}_{10}$ particles collected from meat charbroiling. $J$. Korean Soc. Environ. Eng. 32: 155-164. http://www.jkse e.or.kr/journal/view.php?number=3115

Seo, Y.H., Ku, M.S., Choi, J.W., Kim, K.M., Kim, S.M., Sul, K.H., Jo, H.J., Kim, S.J. and Kim, K.H. (2015). Characteristics of $\mathrm{PM}_{2.5}$ emission and distribution in a highly commercialized area in Seoul, Korea. J. Korean Soc. Atmos. Environ. 31: 97-104. https://doi.org/10.5572/ KOSAE.2015.31.2.097

Received for review, September 16, 2019

Revised, March 25, 2020

Accepted, May 1, 2020 